\title{
Influence of Substrates on the Long-Range Order of Photoelectrodeposited Se-Te Nanostructures
}

Ethan Simonoff, Michael F Lichterman, Kimberly M. Papadantonakis, and Nathan S. Lewis

Nano Lett., Just Accepted Manuscript • Publication Date (Web): 28 Jan 2019

Downloaded from http://pubs.acs.org on January 28, 2019

\section{Just Accepted}

"Just Accepted" manuscripts have been peer-reviewed and accepted for publication. They are posted online prior to technical editing, formatting for publication and author proofing. The American Chemical Society provides "Just Accepted" as a service to the research community to expedite the dissemination of scientific material as soon as possible after acceptance. "Just Accepted" manuscripts appear in full in PDF format accompanied by an HTML abstract. "Just Accepted" manuscripts have been fully peer reviewed, but should not be considered the official version of record. They are citable by the Digital Object Identifier (DOI®). "Just Accepted" is an optional service offered to authors. Therefore, the "Just Accepted" Web site may not include all articles that will be published in the journal. After a manuscript is technically edited and formatted, it will be removed from the "Just Accepted" Web site and published as an ASAP article. Note that technical editing may introduce minor changes to the manuscript text and/or graphics which could affect content, and all legal disclaimers and ethical guidelines that apply to the journal pertain. ACS cannot be held responsible for errors or consequences arising from the use of information contained in these "Just Accepted" manuscripts. 


\title{
INFLUENCE OF SUBSTRATES ON THE LONG-RANGE ORDER OF Photoelectrodeposited SE-TE NANOSTRUCTURES
}

\author{
ETHAN SiMONOFF ${ }^{\dagger}$, MiCHAEL F. LICHTERMAN ${ }^{\dagger}$, KIMBERLy M. PAPADANTONAKIS ${ }^{\dagger}$, \\ NATHAN S. LEWIS ${ }^{\dagger, 1, *}$ \\ 'Division of Chemistry and Chemical Engineering. 127-72, 210 Noyes Laboratory \\ 'Beckman Institute \\ California Institute of Technology \\ Pasadena, CA 91125 \\ *Corresponding Author: nslewis@caltech.edu
}


TABLE OF CONTENTS (TOC) GRAPHIC.

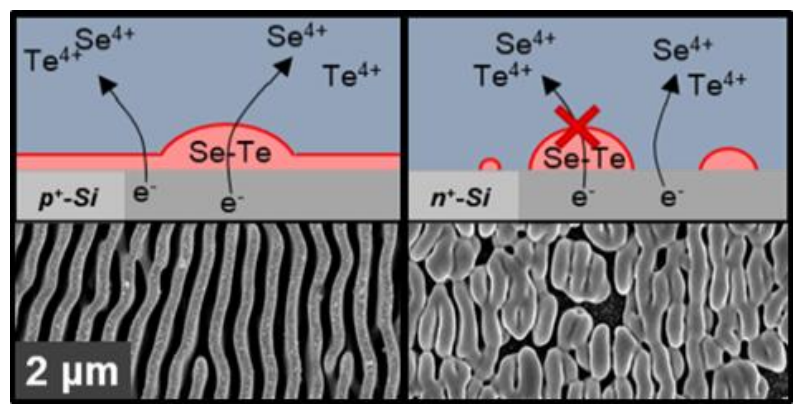

ACS Paragon Plus Environment 


\begin{abstract}
.
The long-range order of anisotropic phototropic Se-Te films grown electrochemically at room temperature under uniform intensity, polarized, incoherent near-IR illumination has been investigated using crystalline (111)-oriented Si substrates doped degenerately with either p- or ntype dopants. Fourier-transform (FT) analysis was performed on large-area images obtained with a scanning electron microscope, and peak shapes in the FT spectra were used to determine the pattern fidelity in the deposited Se-Te films. Under nominally identical illumination conditions, phototropic films grown on $\mathrm{p}^{+}-\mathrm{Si}(111)$ exhibited a higher degree of anisotropy and a more welldefined pattern period than phototropic films grown on $n^{+}-\operatorname{Si}(111)$. Similar differences in the phototropic Se-Te deposit morphology and pattern fidelity on $\mathrm{p}^{+}-\mathrm{Si}$ vs. $\mathrm{n}^{+}-\mathrm{Si}$ were observed when the deposition rate and current densities were controlled for by adjusting the deposition parameters and illumination conditions. The doping-related effects of the Si substrate on the pattern fidelity of the phototropic Se-Te deposits is ascribable to an electrical effect produced by the different interfacial junction energetics between $\mathrm{Se}-\mathrm{Te}$ and $\mathrm{p}^{+}-\mathrm{Si}$ vs $\mathrm{n}^{+}-\mathrm{Si}$ that influences the dynamic behavior during phototropic growth at the Se-Te/Si interface.
\end{abstract}

Keywords: Electrodeposition, photoelectrochemistry, photodeposition, nanopatterning, interface, chalcogenide 
Highly anisotropic nanoscale lamellar patterns spontaneously develop over macroscopic areas during electrodeposition of phototropic Se-Te alloy films onto unpatterned substrates illuminated uniformly by incoherent polarized light. ${ }^{1}$ The lamellae adopt an orientation parallel to the direction of polarization, and the width and periodicity of the lamellae are controlled by the intensity-weighted average wavelength of the illumination. ${ }^{2}$ The patterns of the phototropic SeTe films respond dynamically during growth to changes in the illumination, enabling the templatefree synthesis of complex three-dimensional nanostructures with fully controllable morphologies based on controlling the properties of the incident light during the phototropic growth process. ${ }^{1}$ Phototropic growth may therefore offer an intrinsically three-dimensional approach to the design and synthesis of adaptive, complex, mesostructured materials with a variety of novel properties, including materials with optical properties tailored for use as elements in next-generation optical devices (e.g. lenses, filters, modulators), light absorbers in thin-film solar cells or photodetectors, and mesoscopic materials for supporting thermal or electrochemical catalysts with controlled electronic and ionic conductivity.

The Se-Te alloys are semiconductors with energy-band gaps $\left(\mathbf{E}_{\mathrm{g}}\right)$ that are between those of Se $\left(\mathbf{E}_{\mathrm{g}} \sim 1.85 \mathrm{eV}\right)$ and $\mathrm{Te}\left(\mathbf{E}_{\mathrm{g}} \sim 0.33 \mathrm{eV}\right)$, depending on the ratio of Se to Te as well as the crystallinity of the material. ${ }^{3-6}$ Phototropic growth with consequent optically based nanoscale morphology control has also been observed for PbSe films, suggesting that the phenomenon may be general for semiconductors with short minority-carrier diffusion lengths. ${ }^{7}$ A model that combines full-wave optical simulations with weighted Monte-Carlo mass addition accurately reproduces the average pattern period and morphology for phototropic Se-Te structures grown under multiple and complex optical inputs., ${ }^{2,8,9}$ 
Se-Te photoelectrodeposits exhibit phototropic growth on a variety of substrates, including $\mathrm{Au}$, highly oriented pyrolytic graphite, $\mathrm{n}^{+}-\mathrm{Si}(111)$, and $\mathrm{p}-\mathrm{Si}(100){ }^{1} \quad$ Hence the atomic-level structural properties of the substrate/film interface do not substantially influence the morphology of the resultant photoelectrodeposited phototropic Se-Te film. Electrochemical reactions of semiconductors involve the conduction of charge through either the conduction or valence band, and often are affected by differences in the behavior and distribution of charge carriers under dark or illuminated conditions, as in the anodic etching of $\mathrm{Si}^{10-12}$ Band conduction and the electrochemical behavior of semiconductors are important during the deposition of metals onto structured Si working electrodes, with the work function of the deposited metals influencing the spatial distribution of the electrodeposit, either in the dark or under illumination. ${ }^{13}$ In addition, wavelength-dependent light-absorption profiles have been shown to direct deposition of metal anisotropically onto patterned, photoactive Si microwire arrays. ${ }^{14}$

After an initial light-independent deposition phase, phototropic growth of the Se-Te films results from absorption of light with energy above the Se-Te band gap, producing an electron-hole pair. Photogenerated electrons that reach the Se-Te/electrolyte interface reduce oxidized Se or Te species dissolved in the solution, whereas photogenerated holes are collected at the back contact to the Se-Te film. Holes must be conducted across the back contact, so the energetics of the interface between the phototropically growing semiconducting electrodeposit and the substrate may influence the morphology and growth of the phototropic film. Herein we examine whether and how the substrate influences the development of the lamellar patterns in photoelectrodeposited Se-Te films, with a focus on possible electrical effects due to the energetics of the junction between the substrate and the phototropic semiconducting film.

\section{Matched-Illumination Growth Conditions}


Detailed experimental procedures are provided in the Supporting Information. Se-Te films were deposited potentiostatically from an aqueous bath of $1.00 \mathrm{M} \mathrm{H}_{2} \mathrm{SO}_{4}, 0.020 \mathrm{M} \mathrm{SeO}_{2}$, and 0.010 $\mathrm{M} \mathrm{TeO}_{2}$. The $\mathrm{p}^{+}-\mathrm{Si}$ and $\mathrm{n}^{+}-\mathrm{Si}$ planar substrates had a resistivity $<0.005 \Omega-\mathrm{cm}$ and had a $(111) \pm$ $0.5^{\circ}$ crystal orientation. Unless otherwise noted, all substrates were illuminated with constant, vertically polarized light from a narrow-band light-emitting diode (LED) source producing an intensity-weighted average wavelength of $927 \mathrm{~nm}$ at a nominally uniform power density of $53 \mathrm{~mW}$ $\mathrm{cm}^{-2}$ over the whole substrate. Mass was deposited by cathodic deposition until a total charge density of $-750 \mathrm{mC} \mathrm{cm}^{-2}$ had passed through the working electrode.

Figures 1(a) and (b) show representative scanning-electron microscopy (SEM) images of Se-Te films grown on $\mathrm{p}^{+}-\mathrm{Si}(111)$ and $\mathrm{n}^{+}-\operatorname{Si}(111)$ substrates, respectively. The films grown on $\mathrm{p}^{+}-$ Si exhibited a higher degree of anisotropy along the axis of optical polarization than films grown on $\mathrm{n}^{+}-\mathrm{Si}$, and more defects were apparent in the patterns of the $\mathrm{n}^{+}-\mathrm{Si} / \mathrm{Se}-\mathrm{Te}$ films than in the $\mathrm{p}^{+}$Si/Se-Te films. Figures S1(a) and (b) provide high-resolution, low-magnification images showing wide areas of the photoelectrodeposited Si/Se-Te films that contain the regions shown in Figures 1(a) and (b).

Figures 1(c) and (d) show two-dimensional Fourier transforms (2D FT) of wide-area images of phototropic Se-Te films grown on $\mathrm{p}^{+}-\mathrm{Si}$ and $\mathrm{n}^{+}-\mathrm{Si}$ substrates. The 2D FT data were converted to and analyzed in the polar coordinate system where the radial coordinate, $r$, is the linear distance from the center of the FT, equivalent to the periodicity of the pattern in real space. The angular coordinate, $\theta$, is the angle formed between the position of the radial coordinate and the positive $\mathrm{x}$ axis in Cartesian coordinates, equivalent to the direction of the pattern. Thusly, the horizontal component of the 2D FT was evaluated where $\theta=0$ (and $r=x$ ) along the direction perpendicular to the polarization vector used during film growth, and reflects the spacing of the 
lamellae in the SEM images, with a narrow band in the horizontal component of the 2D FT corresponding to a lamellar pattern with a highly defined period. The vertical component of the 2D FT was then evaluated at a distance, $r$, corresponding to the position of the primary FT band as determined by the peak position in the horizontal direction. The vertical component is parallel to the polarization vector used during film growth and reflects the alignment of the lamellae with the axis of polarization. A narrow band in the vertical component of the $2 \mathrm{D}$ FT corresponds to a highly anisotropic pattern, approaching perfectly parallel and straight lamellae.

Figures 1(e) and (f) show the horizontal and vertical surface profiles that were extracted from the bands corresponding to the primary periods in the 2D FTs shown in Figures 1(c) and (d). For the horizontal and vertical profiles, the bands were sharper for $\mathrm{p}^{+}-\mathrm{Si} / \mathrm{Se}-\mathrm{Te}$ than for $\mathrm{n}^{+}-\mathrm{Si} / \mathrm{Se}-$ Te films, consistent with a more defined pattern, and straighter lamellae, for Se-Te films grown on $\mathrm{p}^{+}$-Si substrates than on $\mathrm{n}^{+}-\mathrm{Si}$ substrates. The horizontal and vertical profiles were fitted to Lorentzian functions, and the full-widths at half maximum (FWHMs) of the fitted peaks provide figures-of-merit for the uniformity of the lamellar Se-Te structure. For horizontal FWHMs The FWHMs of the fits to the horizontal profiles were $1.49 \mu \mathrm{m}^{-1}$ and $1.77 \mu \mathrm{m}^{-1}$ for $\mathrm{p}^{+}-\mathrm{Si} / \mathrm{Se}-\mathrm{Te}$ and $\mathrm{n}^{+}$Si/Se-Te films, respectively. For the vertical profiles, the FWHMs were $30.9^{\circ}$ and $57.9^{\circ}$ for $\mathrm{p}^{+}$$\mathrm{Si} / \mathrm{Se}-\mathrm{Te}$ and $\mathrm{n}^{+}-\mathrm{Si} / \mathrm{Se}-\mathrm{Te}$ films, respectively. Average horizontal FWHM values for samples prepared under nominally identical conditions were $1.44 \pm 0.26 \mathrm{um}^{-1}$ and $1.79 \pm 0.07 \mathrm{um}^{-1}$ for $\mathrm{p}^{+}$$\mathrm{Si} / \mathrm{Se}-\mathrm{Te}$ and $\mathrm{n}^{+}-\mathrm{Si} / \mathrm{Se}-\mathrm{Te}$ films, respectively. For the vertical FWHM values, averages for $\mathrm{p}^{+}-$ $\mathrm{Si} / \mathrm{Se}-\mathrm{Te}$ were $31.3^{\circ} \pm 1.0^{\circ}$; for $\mathrm{n}^{+}-\mathrm{Si} / \mathrm{Se}-\mathrm{Te}$ films, averages were $63.4^{\circ} \pm 10.1^{\circ}$

Films grown on the different substrates yielded different locations in reciprocal Fourier space of the maxima of the peaks fitted to the horizontal surface profiles, with higher values in reciprocal Fourier space corresponding to smaller periods in real space. The fit to the peak 
associated with $\mathrm{p}^{+}-\mathrm{Si} / \mathrm{Se}-\mathrm{Te}$ films was centered at $2.79 \mu^{-1}$, corresponding to an average period of $358 \mathrm{~nm}$, whereas the fit to the peak associated with $\mathrm{n}^{+}-\mathrm{Si} / \mathrm{Se}-\mathrm{Te}$ films was centered at $2.47 \mu^{-}$ ${ }^{1}$, corresponding to an average period of $405 \mathrm{~nm}$. This increase in the average period results from the higher degree of disorder in the pattern, which led to a less closely packed pattern for the $\mathrm{n}^{+}-$ $\mathrm{Si} / \mathrm{Se}-\mathrm{Te}$ films as compared to the $\mathrm{p}^{+}-\mathrm{Si} / \mathrm{Se}-\mathrm{Te}$ films.

\section{Nucleation Dynamics}

To elucidate the development of the patterns in the phototropically grown films as well as any differences in how the phototropic patterns develop on the two differently doped types of Si substrates, the phototropic growth of Se-Te films on $\mathrm{p}^{+}-\mathrm{Si}$ or $\mathrm{n}^{+}-\mathrm{Si}$ was observed at several steps early in the photoelectrodeposition process. Figure 2 shows the structures observed during nucleation and development of the phototropic Se-Te films. At low levels of mass deposited and cathodic charge density passed $\left(-0.75 \mathrm{mC} \mathrm{cm}^{-2}\right)$, the morphology of the phototropic Se-Te deposit was nearly identical on both substrates, with more uniform nucleation on $\mathrm{p}^{+}-\mathrm{Si}$ (Figure $2 \mathrm{a}$ ), and the initial development of some larger islands on $\mathrm{n}^{+}-\mathrm{Si}$ (Figure 2f). On $\mathrm{p}^{+}-\mathrm{Si}(111)$ substrates, as additional cathodic charge density $\left(-3.75 \mathrm{mC} \mathrm{cm}^{-2}\right)$ was passed, the deposition density sharply increased, resulting in a thin, continuous film (Figure $2 b)$. In contrast, on $n^{+}-\operatorname{Si}(111)$ substrates, larger nucleated sites continued to develop (Figure $2 \mathrm{~g}$ ). At the next step in cathodic charge density $\left(-37.5 \mathrm{mC} \mathrm{cm}^{-2}\right)$, a nearly continuous film of nucleation sites was observed on $\mathrm{p}^{+}-\mathrm{Si}$ (Figure 2c) whereas on $\mathrm{n}^{+}-\mathrm{Si}$ the film remained discontinuous even though the nucleation sites were larger than for the previous current step (Figure $2 \mathrm{~h})$. At the subsequent charge density step $\left(-75 \mathrm{mC} \mathrm{cm}^{-}\right.$ ${ }^{2}$ ), on $\mathrm{p}^{+}-\mathrm{Si}$ the nucleation sites had merged into a lamellar pattern (Figure $2 \mathrm{~d}$ ), whereas void space and islanded nucleation sites were still present on $\mathrm{n}^{+}-\mathrm{Si}$ even though some nucleation sites had merged (Figure 2i). After the final charge density step $\left(750 \mathrm{mC} \mathrm{cm}^{-2}\right)$, the phototropically grown 
films on $\mathrm{p}^{+}-\mathrm{Si}$ (Figure 2e) and $\mathrm{n}^{+}-\mathrm{Si}$ (Figure $2 \mathrm{j}$ ) had developed into structures with mutually similar lamellar patterns, but with mutually distinctive, and clearly identifiable differences in the pattern fidelity.

\section{Junction Analysis}

To further investigate the reasons for the variation in nucleation dynamics and resulting film morphologies on the two types of Si substrates, the electrical characteristics of junctions formed between $\mathrm{Se}-\mathrm{Te}$ films and $\mathrm{p}^{+}-\mathrm{Si}$ or $\mathrm{n}^{+}-\mathrm{Si}$ substrates were investigated (see Supporting Information for detailed experimental methods describing solid-state measurements). Figure $3 \mathrm{a}$ shows the current density versus voltage, $J-V$, behavior of $\mathrm{Se}-\mathrm{Te}$ deposited on $\mathrm{p}^{+}-\mathrm{Si}$ or $\mathrm{n}^{+}-\mathrm{Si}$. The linear $J-V$ relationship for Se-Te deposited on $\mathrm{p}^{+}-\mathrm{Si}$ indicates an ohmic contact, whereas the $J-V$ relationship between $\mathrm{Se}-\mathrm{Te}$ and $\mathrm{n}^{+}-\mathrm{Si}$ was non-linear. The $\mathrm{Si}$ substrates had nominally mutually equal resistivity, thickness, and crystal orientations, and nominally only differed in dopant type and Fermi level. The lower current density observed for Se-Te films grown on $\mathrm{n}^{+}-\mathrm{Si}$ relative to the current density for $\mathrm{Se}-\mathrm{Te}$ grown on $\mathrm{p}^{+}-\mathrm{Si}$ at the same applied potential is thus consistently ascribable to the presence of a non-ohmic voltage drop at the $\mathrm{n}^{+}-\mathrm{Si} / \mathrm{Se}-\mathrm{Te}$ junction.

Figure $3 b$ shows the change in current density with time for representative Se-Te films photoelectrodeposited on $\mathrm{p}^{+}-\mathrm{Si}$ or $\mathrm{n}^{+}-\mathrm{Si}$ substrates. The substrates were held for $\sim 200 \mathrm{~s}$ at a potential of $-0.065 \mathrm{~V}$ (for $\mathrm{p}^{+}-\mathrm{Si}$ ) and $-0.200 \mathrm{~V}$ (for $\mathrm{n}^{+}-\mathrm{Si}$ ) vs. $\mathrm{Ag} / \mathrm{AgCl}$, under nominally mutually identical injection conditions $\left(53 \mathrm{~mW} \mathrm{~cm}{ }^{-2}\right.$ illumination power). The light was then blocked for 10 s. Throughout the photoelectrodeposition, the cathodic photocurrent densities for phototropic SeTe growth on $\mathrm{p}^{+}-\mathrm{Si}$ were greater than those for phototropic Se-Te growth on $\mathrm{n}^{+}-\mathrm{Si}$ (Figure $3 \mathrm{~b}$ ); for example, immediately prior to the light being blocked, a photocurrent density of $-2.44 \mathrm{~mA} \mathrm{~cm}^{-2}$ was measured for Se-Te on $\mathrm{p}^{+}-\mathrm{Si}$, whereas a photocurrent density of $-1.89 \mathrm{~mA} \mathrm{~cm}^{-2}$ was observed 
for Se-Te on $\mathrm{n}^{+}$-Si. Additionally, the dark current comprised up a larger proportion of the total current for films grown on $\mathrm{n}^{+}-\mathrm{Si}$ than for films grown on $\mathrm{p}^{+}-\mathrm{Si}$. For example, in the dark, $-0.09 \mathrm{~mA}$ $\mathrm{cm}^{-2}$ was passed by Se-Te on $\mathrm{p}^{+}-\mathrm{Si}$, while $-0.47 \mathrm{~mA} \mathrm{~cm}^{-2}$ was passed by Se-Te on $\mathrm{n}^{+}-\mathrm{Si}$. The photocurrent from the Se-Te film was negative, indicating that the film exhibited p-type conductivity during the deposition. These results are characteristic of the general morphology produced by inorganic phototropic growth of Se-Te films on $\mathrm{p}^{+}-\mathrm{Si}$ or $\mathrm{n}^{+}-\mathrm{Si}$ (Figure S4).

Figure S3 shows the ultraviolet photoelectron spectroscopy (UPS) data for as-deposited and for sputter-cleaned Se-Te films. After removal of a surface oxide via sputter-cleaning, the work function of Se-Te was measured to be $\sim 5 \mathrm{eV}$, and the position of the valence-band maximum (VBM) relative to the Fermi level $\left(E_{F}\right)$, or VBM $-E_{F}$, was $\sim 395 \mathrm{meV}$ for Se-Te deposited on both $\mathrm{n}^{+}-\mathrm{Si}$ and $\mathrm{p}^{+}-\mathrm{Si}$ substrates. For a film of 60-80 at. $\% \mathrm{Te}$, the optical bandgap, $E_{g}$, of Se-Te has been experimentally determined to be $1.06 \mathrm{eV} .^{6}$

Figure 4 shows a simplified band diagram ${ }^{15}$ for Se-Te in contact with $\mathrm{p}^{+}-\mathrm{Si}$ or $\mathrm{n}^{+}-\mathrm{Si}^{16}$ During the deposition of Se-Te, photogenerated electrons, i.e., the minority carriers, are collected at the dynamic semiconductor-solution interface and result in mass addition to the growing film. For the photodriven mass-addition process to occur, the photogenerated holes must thus be collected at the $\mathrm{Si} / \mathrm{Se}-\mathrm{Te}$ junction before recombining. In the case of $\mathrm{p}^{+}-\mathrm{Si} / \mathrm{Se}-\mathrm{Te}$ films, the observed ohmic contact and proximity of the observed work function measured for Se-Te to the valence-band maximum of $\mathrm{Si}$ suggest a minimal barrier to hole collection at that interface. Conversely, the difference between the work functions of Se-Te and $\mathrm{n}^{+}-\mathrm{Si}$ implies the presence of a substantial barrier to hole collection, thus inhibiting the flow of photocurrent into solution and preventing mass addition to the electrodeposit. 
The observed junction behavior between Se-Te and the Si growth substrates can explain the nucleation dynamics observed in Figure 2. The non-ohmic contact between $\mathrm{n}^{+}-\mathrm{Si}$ and Se-Te would enhance electrical isolation of the nucleated Se-Te sites, due to the potential drop at the junction with $\mathrm{n}^{+}-\mathrm{Si}$. The variation in the material in contact with the solution would lead to a surface of mixed barrier height across the partially nucleated $n^{+}-S i$ substrate. This behavior is consistent with the sustained discontinuous nature of the film grown on $\mathrm{n}^{+}-\mathrm{Si}$ (vs. the continuous films present on $\mathrm{p}^{+}-\mathrm{Si}$ ), even at late stages of deposition.

\section{Matched Deposition-Rate Conditions}

Under nominally mutually identical illumination power, Se-Te films phototropically grown on $\mathrm{p}^{+}-\mathrm{Si}$ substrates were observed to exhibit greater photocurrent densities, and thus to grow faster, than phototropically grown Se-Te films on $\mathrm{n}^{+}-\mathrm{Si}$ substrates. Se-Te films were therefore grown on $\mathrm{p}^{+}-\mathrm{Si}$ substrates with the applied potential and illumination power tuned such that the photocurrent densities, and the ratios of light to dark current density, matched to within $15 \%$ the values for films grown on $\mathrm{n}^{+}$-Si. Figure 5 shows three such matched pairs of growths, providing examples of samples having matched rates of deposition for relatively low $\left(\sim 0.5 \mathrm{~mA} \mathrm{~cm}^{-2}\right)$, intermediate $(\sim 0.7$ $\left.\mathrm{mA} \mathrm{cm}{ }^{-2}\right)$, and high $\left(\sim 1.0 \mathrm{~mA} \mathrm{~cm}^{-2}\right)$ total current densities. The films deposited on $\mathrm{p}^{+}-$Si exhibited less defective patterns and straighter, more anisotropic lamellae, whereas films on $\mathrm{n}^{+}-\mathrm{Si}$ exhibited patchier morphologies and more defective patterns. These observations correlated with much sharper horizontal and vertical 2D FT peaks (Table 1) for phototropic $\mathrm{p}^{+}-\mathrm{Si} / \mathrm{Se}-\mathrm{Te}$ films than for phototropic $\mathrm{n}^{+}-\mathrm{Si} / \mathrm{Se}-\mathrm{Te}$ films.

Films grown on $\mathrm{n}^{+}-\mathrm{Si}$ exhibited an increased photocurrent density at more negative applied potentials whereas films grown on $\mathrm{p}^{+}-\mathrm{Si}$ showed less relative change in the observed photocurrent density with applied potential (Figure S4). Figure S5 shows the FWHMs for the 2D FTs for the 
films deposited at varied growth rates on $\mathrm{p}^{+}-\mathrm{Si}$ or $\mathrm{n}^{+}-\mathrm{Si}$ substrates. Films grown on $\mathrm{p}^{+}-\mathrm{Si}$ at low rates resulted in narrower 2D FT bands than films deposited at higher rates. The opposite trend was observed for films grown on $\mathrm{n}^{+}-\mathrm{Si}$, with films grown on $\mathrm{n}^{+}-\mathrm{Si}$ at lower relative rates having broader 2D FT bands than films grown at high rates. Figures S6 and S7 show that the same general trend was observed for films deposited on metals of varying work function, with Se-Te deposited on metal substrates having work functions closely aligned with $\mathrm{Se}-\mathrm{Te}$ (i.e., $\mathrm{Au}, \phi_{\mathrm{m}}=5.3-5.4 \mathrm{eV}$ ) exhibiting higher photocurrent densities, and less defective patterns, than films deposited on substrates having a work function misaligned with $\mathrm{Se}-\mathrm{Te}\left(\mathrm{i} . \mathrm{e} ., \mathrm{Ti}, \phi_{\mathrm{m}}=4.33 \mathrm{eV}\right) .{ }^{17} \mathrm{In}$ addition, Figure S8 shows the $J-V$ behavior of Se-Te films on substrates that exhibited better electrical contact than was observed for Ti contacts to Se-Te.

Nucleation may play a role in the effect of deposition rate on the fidelity of the Se-Te film pattern. To achieve higher rates of growth, the required relative applied potentials were more negative, leading to decreases in the band bending at the interface between $\mathrm{n}^{+}-\mathrm{Si}$ and Se-Te. Consequently, Se-Te nucleation may be denser on $\mathrm{n}^{+}-\mathrm{Si}$ at these more negative potentials. Conversely, the ohmic contact between Se-Te and $\mathrm{p}^{+}$-Si suggests negligible barrier to nucleation at less negative potentials. In both cases, the observed higher fidelity patterns are consistent with expectations for the formation of more continuous and thin film nucleation relative to island nucleation of Se-Te deposits.

In summary, in all cases examined herein, the fidelity of the pattern was greater for phototropic Se-Te films grown on $\mathrm{p}^{+}-\mathrm{Si}$ substrates than for phototropic Se-Te films grown on $\mathrm{n}^{+}-$ Si. Parameterization using only conditions of deposition rate and illumination power does not allow prediction of the pattern fidelity or of the observed differences in film properties on either substrate. However, the energetics of the junction between the phototropic Se-Te film and the 
substrate influences the nucleation dynamics and subsequent morphological variation and pattern fidelity, thus providing an example of the influence of interfacial electrical effects, as opposed to structural effects, of the substrate on the morphology of phototropically grown Se-Te films.

\section{SUPPORTING INFORMATION.}

In-depth experimental methods and materials used, additional scanning electron micrographs, plotted XPS/UPS data, plots of observed photoelectrochemical quantities and calculated figures of merit, results/discussion for experiments on metallic substrates, discussions on nucleation density, tabulated details for all fabricated samples.

\section{AUTHOR INFORMATION.}

Corresponding Author

*Email: nslewis@caltech.edu.

\section{Notes}

The authors declare no competing financial interest.

\section{ACKNOWLEDGEMENTS.}

This work is part of the 'Light-Material Interactions in Energy Conversion' Energy Frontier Research Center funded by the U.S. Department of Energy, Office of Science, Office of Basic Energy Sciences under Award Number DE-SC0001293.

XPS and UPS data were collected at the Molecular Materials Research Center of the Beckman Institute of the California Institute of Technology. 


\section{REFERENCES.}

1. $\quad$ Sadtler, B.; Burgos, S. P.; Batara, N. A.; Beardslee, J. A.; Atwater, H. A.; Lewis, N. S. Proc Natl Acad Sci U S A 2013, 110, 19707-12.

2. Carim, A. I.; Batara, N. A.; Premkumar, A.; Atwater, H. A.; Lewis, N. S. Nano Lett 2015, 15, 7071-7076.

3. $\quad$ Bhatnagar, A. K.; Srivastava, V.; Reddy, K. V. Appl Phys Lett 1998, 73, 2426-2428.

4. $\quad$ Reddy, K. V.; Bhatnagar, A. K. J Phys D Appl Phys 1992, 25, 1810-1816.

5. $\quad$ Beyer, W.; Mell, H.; Stuke, J. phys status solidi (b) 1971, 45, 153-162.

6. El-Korashy, A.; El-Zahed, H.; Zayed, H. A.; Kenawy, M. A. Solid State Commun 1995, 95, 335-339.

7. $\quad$ Carim, A. I.; Hamann, K. R.; Batara, N. A.; Thompson, J. R.; Atwater, H. A.; Lewis, N. S. J Am Chem Soc 2018, 140, 6536-6539.

8. Carim, A. I.; Batara, N. A.; Premkumar, A.; Atwater, H. A.; Lewis, N. S. ACS Nano 2016, 10, 102-11.

9. $\quad$ Carim, A. I.; Batara, N. A.; Premkumar, A.; May, R.; Atwater, H. A.; Lewis, N. S. Nano Lett 2016, 16, 2963-8.

10. Matthias, S.; Müller, F.; Jamois, C.; Wehrspohn, R. B.; Gösele, U. Adv Mater 2004, 16, 2166-2170.

11. Lévy-Clément, C. J Electrochem Soc 1994, 141, 958.

12. Lehmann, V. J Electrochem Soc 1990, 137, 653.

13. Ogata, Y.; Kobayashi, K.; Motoyama, M. Curr Opin Solid St M 2006, 10, 163-172.

14. Dasog, M.; Carim, A. I.; Yalamanchili, S.; Atwater, H. A.; Lewis, N. S. Nano Lett 2016, $16,5015-21$.

15. Zhang, Z.; Yates, J. T., Jr. Chem Rev 2012, 112, 5520-51.

16. Novikov, A. Solid-State Electronics 2010, 54, 8-13.

17. Skriver, H. L.; Rosengaard, N. M. Physical Review B 1992, 46, 7157-7168. 

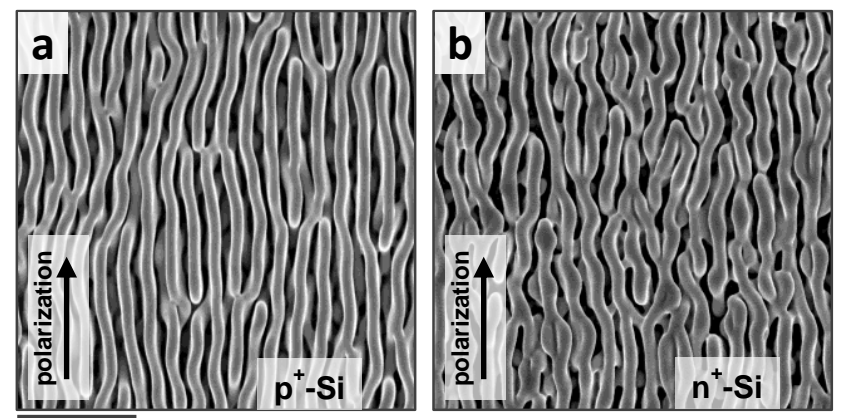

\section{$2 \mu \mathrm{m}$}
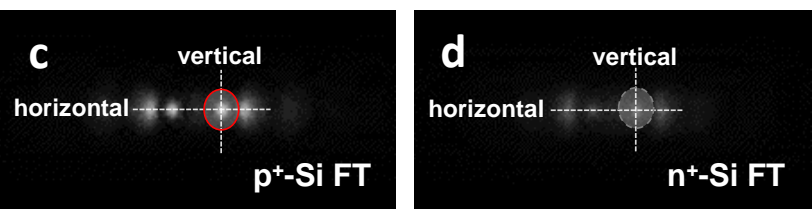

$10 \mathrm{\mu m}^{-1}$
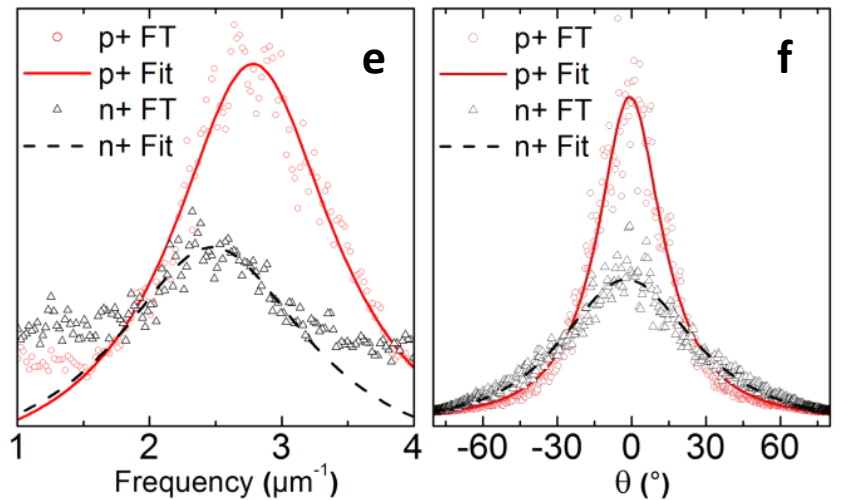

Figure 1. Representative SEM images of SeTe photoelectrodeposited on (a) $\mathrm{p}^{+}-\mathrm{Si}$ and (b) $\mathrm{n}^{+}-\mathrm{Si}$ substrates using vertically polarized illumination with $\lambda=927 \mathrm{~nm}$ and a power density of $53 \mathrm{~mW} \mathrm{~cm}{ }^{-2}$. (c) and (d) $2 \mathrm{D}$ FT spectra generated from wide-area SEM images including the regions depicted in (a) and (b), respectively, with primary FT bands highlighted. Co-plotted (e) horizontal (normal to polarization) and (f) vertical (parallel to polarization) surface profiles of integrated intensity and Lorentzian curve fits for the primary FT bands in the 2D FT spectra in (c) and (d). 


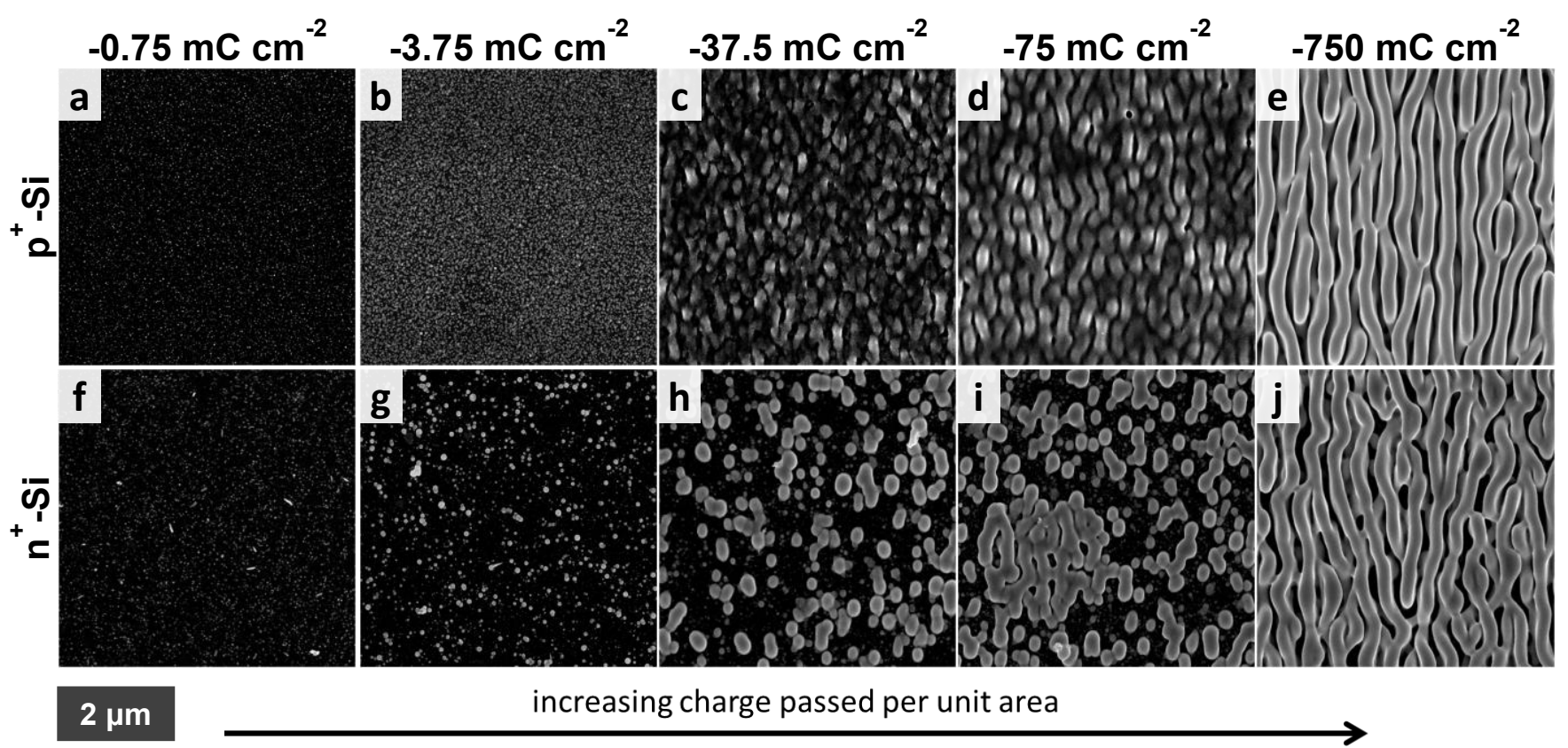

Figure 2. Series of SEM images demonstrating films with characteristic amounts of charge passed (mass deposited) per unit area on (a-e) $\mathrm{p}^{+}-\mathrm{Si}$ and (f-j) $\mathrm{n}^{+}-\mathrm{Si}$ with (a), (f) at $-0.75 \mathrm{mC} \mathrm{cm}^{-2}$; (b), (g) at $-3.75 \mathrm{mC} \mathrm{cm}^{-2}$; (c), (h) at $-37.5 \mathrm{mC} \mathrm{cm}^{-2}$; (d), (i) at $75 \mathrm{mC} \mathrm{cm}^{-2}$; and (e), (j) at $-750 \mathrm{mC} \mathrm{cm}^{-2}$. 

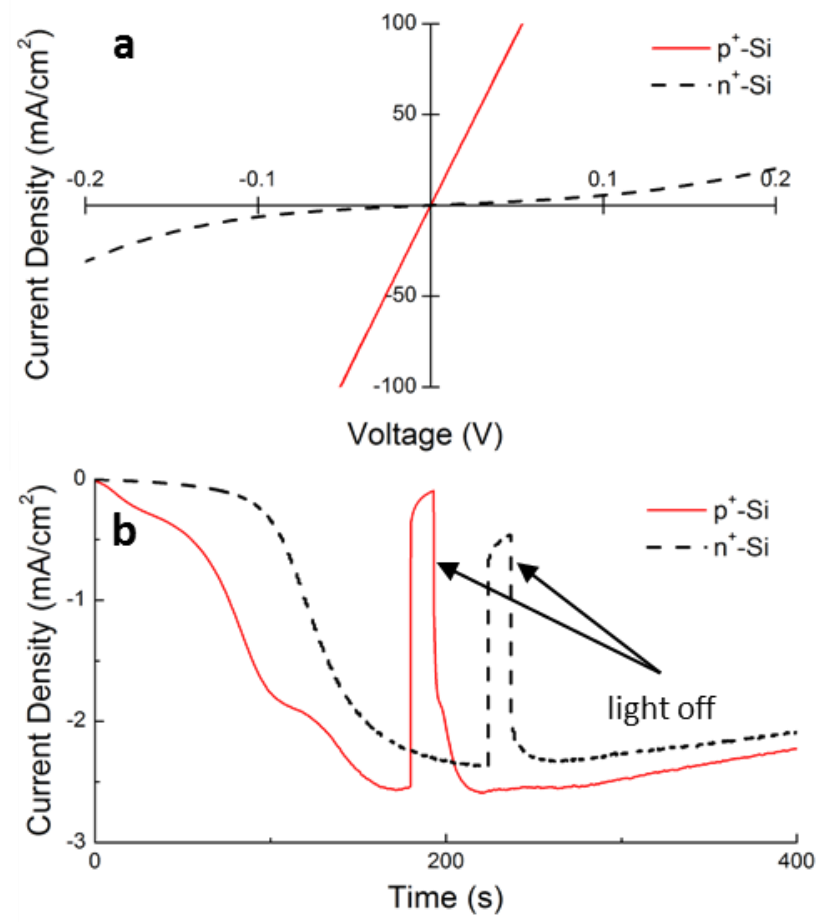

Figure 3. (a) Current-voltage behavior of $\mathrm{Se}-\mathrm{Te}$ on $\mathrm{p}^{+}-\mathrm{Si}$ and $\mathrm{n}^{+}-\mathrm{Si}$. (b) Chopped-light chronoamperometry experiments showing the ratio of light to dark current density for $\mathrm{Se}-\mathrm{Te}$ films representative of those grown on $\mathrm{p}^{+}-\mathrm{Si}$ and $\mathrm{n}^{+}-\mathrm{Si}$. 

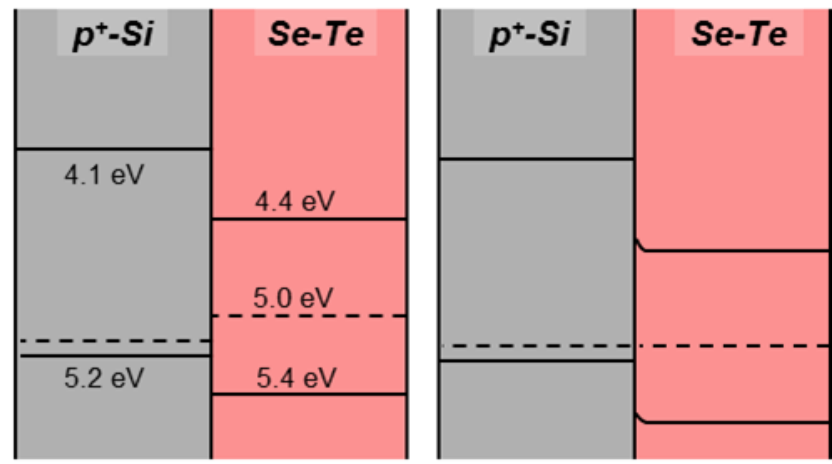

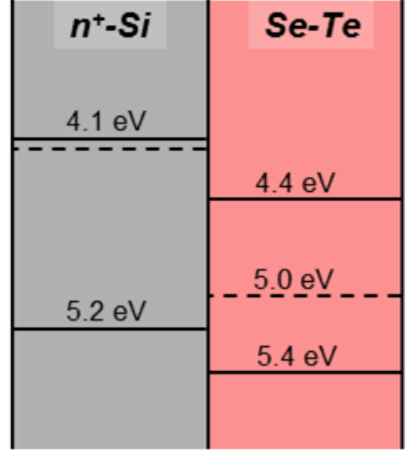

Unequilibrated

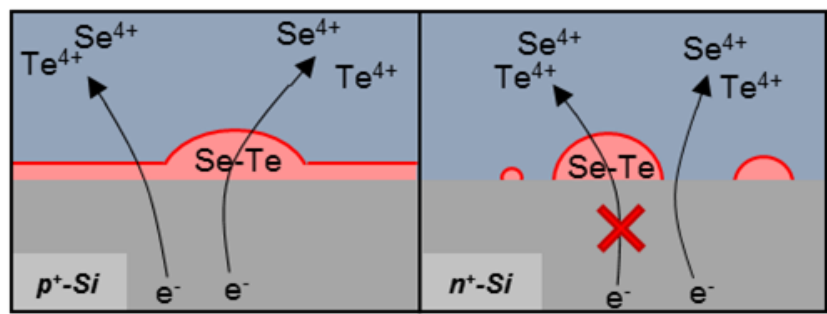

Figure 4. Simplified band diagrams showing the energies of the band positions relative to the vacuum level and the expected trends in the equilibration of the junctions formed by $\mathrm{n}^{+}-\mathrm{Si}$ or $\mathrm{p}^{+}-\mathrm{Si}$ with Se-Te. Lower panel shows a schematic with the hypothesized preferential pathways for mass deposition during the electrodeposition of Se-Te. In the case of the $n^{+}-\mathrm{Si} / \mathrm{Se}-\mathrm{Te}$ interface, the non-ohmic potential drop inhibits deposition onto nucleated Se-Te sites. 


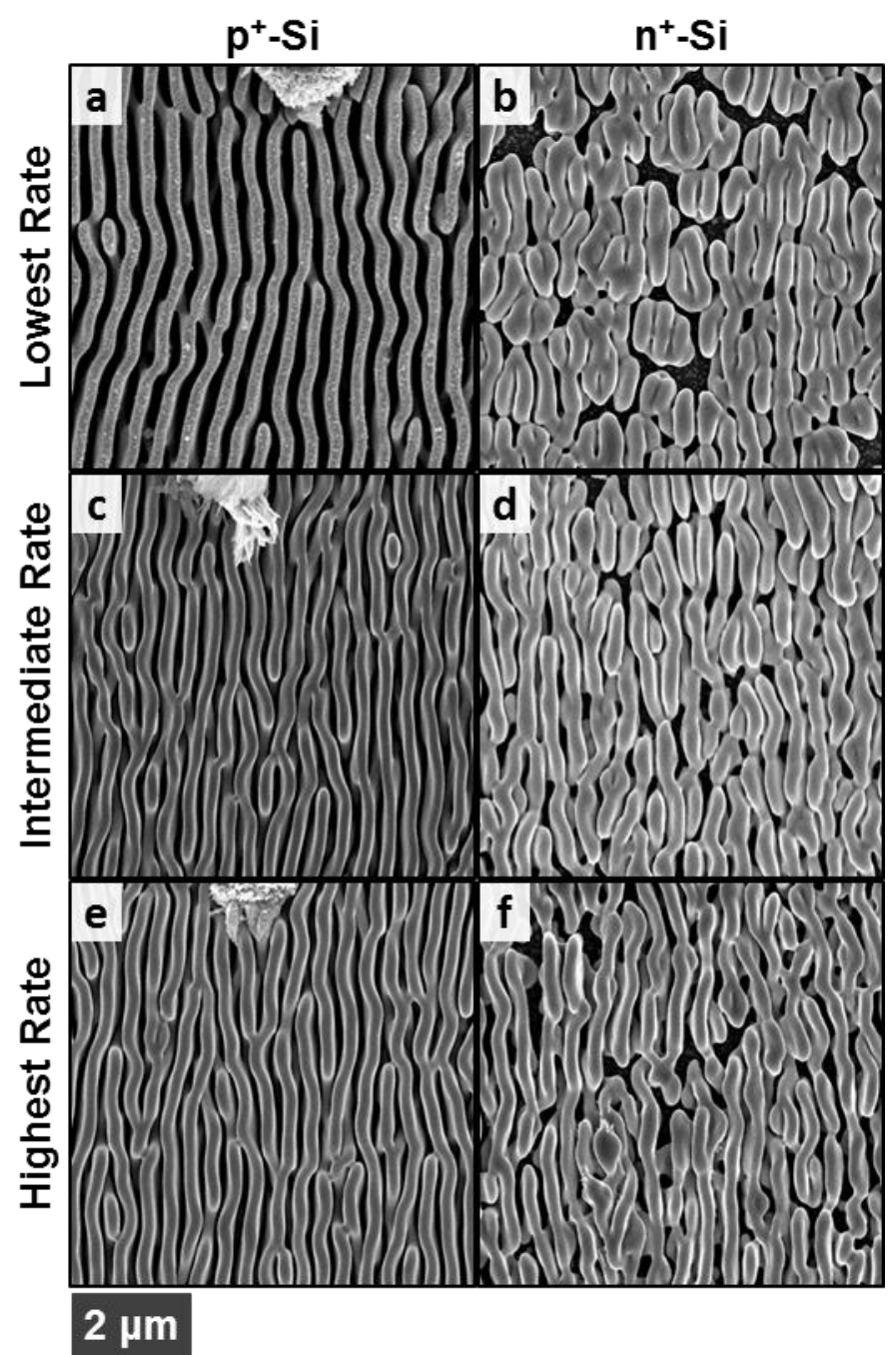

Figure 5. Se-Te films grown at (a), (b) low, $\sim 0.5 \mathrm{~mA} \mathrm{~cm}^{-}$ ${ }^{2}$; (c), (d) intermediate, $\sim 0.7 \mathrm{~mA} \mathrm{~cm}^{-2}$; and (e), (f) high, $\sim 1.0$ $\mathrm{mA} \mathrm{cm}{ }^{-2}$, matched relative deposition rates on (a), (c), (e) $\mathrm{p}^{+}-\mathrm{Si}$ and (b), (d), (f) $\mathrm{n}^{+}-\mathrm{Si}$. 
Table 1. Growth Parameters and FT Analysis of Structures Grown with Matching Rates of Deposition

\begin{tabular}{|c|c|c|}
\hline & \multicolumn{2}{|c|}{ growth substrate } \\
\hline & $p+S i$ & $n+S i$ \\
\hline $\begin{array}{l}\text { Lowest Growth Rate } \\
\quad \text { peak current density }\left(\mathrm{mA} \mathrm{cm}^{-2}\right)\end{array}$ & 0.515 & 0.483 \\
\hline light-to-dark current ratio & 2.22 & 2.41 \\
\hline FT horizontal FWHM $\left(\mu \mathrm{m}^{-1}\right)$ & 0.59 & 2.48 \\
\hline FT vertical FWHM $\left(^{\circ}\right)$ & 33.7 & 104.2 \\
\hline $\begin{array}{l}\text { Intermediate Growth Rate } \\
\quad \text { peak current density }\left(\mathrm{mA} \mathrm{cm}^{-2}\right)\end{array}$ & 0.685 & 0.705 \\
\hline light-to-dark current ratio & 2.74 & 3.17 \\
\hline FT horizontal FWHM $\left(\mu \mathrm{m}^{-1}\right)$ & 1.10 & 2.51 \\
\hline FT vertical FWHM $\left(^{\circ}\right)$ & 30.1 & 72.9 \\
\hline $\begin{array}{l}\text { Highest Growth Rate } \\
\quad \text { peak current density }\left(\mathrm{mA} \mathrm{cm}^{-2}\right)\end{array}$ & 1.031 & 1.077 \\
\hline light-to-dark current ratio & 3.91 & 4.21 \\
\hline FT horizontal FWHM $\left(\mu \mathrm{m}^{-1}\right)$ & 1.00 & 1.73 \\
\hline FT vertical FWHM $\left(^{\circ}\right)$ & 31.4 & $\mathbf{5 7 . 3}$ \\
\hline
\end{tabular}

